\title{
Assessment of the Quality of Pulp Fibers by Short Span Tensile Analysis
}

Edmond L. Graminski and Keith Bonin

Polymer Science and Standards Division Center for Materials Science National Bureau of Standards Washington, D.C. 20234

Progress Report Covering the Period

October 1, 1977 through September 30, 1978.

October 1979

Prepared for:

$-Q C$

100 U.S. Department of Energy Washington, D.C. 20545 

NBSIR 79-1914

\section{ASSESSMENT OF THE QUALITY OF PULP FIBERS BY SHORT SPAN \\ TENSILE ANALYSIS}

Edmond L. Graminski and Keith Bonin

Polymer Science and Standards Division

Center for Materials Science

National Bureau of Standards

Washington, D.C. 20234

Progres: Report Covering the Period

Octoher 1, 1977 through September 30, 1978.

October 1979

Prepared for:

U.S. Department of Energy

Washington, D.C. 20545

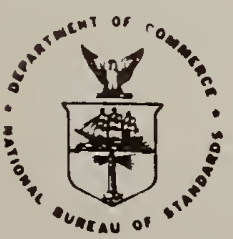

U.S. DEPARTMENT OF COMMERCE, Juanita M. Kreps, Secretary

Luther H. Hodges, Jr., Under Secretary

Jordan J. Baruch. Assistant Secretary for Science and Technology

NATIONAL BUREAU OF STANDARDS, Ernest Ambler, Director 



\section{Page}

1. Summary

2. Introduction

3. Experimental 4

4. Results and Discussion

5. Conclusions

8

6. Bibliography 

1. Summary

The strength of paper is dependent to a large extent on the strength of individual pulp fibers. Regardless of its importance, however, fiber strength is almost never determined as it necessitates the testing of single fibers which is very tedious and time consuming. Fiber strength is usually assessed only when it is critical as in the evaluation of a new pulping process.

Recent studies have shown that the tensile strength of softwood fibers depends not only on the fibril angle of the $S_{2}$ layer, but also on the defects in fibers which are distributed randomly within ${ }^{2}$ and among fibers. The defects are formed during the pulping and mechanical action processes. When waste paper is recycled, the fibers are subjected a second time to chemical and mechanical action processes increasing the possibility of forming fiber defects.

Understandably, there is considerable uncertainty about the fiber quality of recycled pulps and unless the waste paper quality is quite well known in advance, it will not be used to make anything other than low grade paper products. Unfortunately, most waste paper is not well characterized and frequently is contaminated, and even though the waste paper may consist of high quality fibers, the waste paper will be used only for low grade paper products. Since the supply of low grade waste paper exceeds the demand, means will have to be developed for optimizing the utilization of low grades of waste paper if the rate of paper recycling is to increase. Much of the uncertainty of fiber quality could be dispelled if a rapid and reliable method for assessing fiber quality were developed.

In short span tensile testing of paper the failure load decreases as the span, or initial distance between grips, of the specimen increases, because the number of fibers traversing the span decreases. The rate of the decrease in failure load is dependent on the fiber length distribution. For a given fiber length distribution, the rate of decline in failure load with increasing span should be minimal if all of the fibers are perfect. As the quality of the fibers decreases, the rate of decline in failure load with increasing span should increase. It would appear, then, that the slope of a failure load-span length plot for a pulp, having a specific fiber length distribution, would be a measure of fiber quality.

A kraft and a sulfite wood pulp, prepared from a common wood source, were used in this investigation. The purpose of this was to evaluate two pulps having nominally identical fiber length distributions, but greatly different fiber qualities. Handsheets, having a weight of 2.5 and $5.0 \mathrm{~g} / \mathrm{m}^{2}$, from unbeaten and beaten pulps were prepared and tested to tensile failure at spans ranging from $5--500 \mu m$. The instrument used to determine the short span tensile strengths was specially designed to provide a nominally constant rate of jaw separation. Transducers for the simultaneous measurement of load and jaw separation were suitably located on the instrument.

Good linear plots were obtained when the log of the failure load was plotted against span length. There was essentially no difference in the slopes for the unbeaten kraft and sulfite pulps but there was a large difference in the slopes for the beaten pulps. This difference in behavior between the beaten and unbeaten pulps may be due to the differences in the wet plasticity of the unbeaten fibers at the time of handsheet preparation. 
As bonding increases, more and more fibers become load-bearing, resulting in higher loads at the break, especially at the larger spans. In addition, the probability of finding a defect within a bonded area increases as the relative bonded area increases. Defects located within a bonded area are likely to respond to tensile stresses differently. Furthermore, the defect might even become "repaired" or "healed" when located within a bond area. Because of these factors, it is essential that the interfiber bonding in all test handsheets be at an equivalent level for all pulps. Otherwise, the test results could be deceptive.

There appears to be little, if any, fiber slippage from under the clamps with the low density sheets. Extrapolations of the log failure load-span length plots to zero span are in good agreement with the failure loads obtained at $5 \mu \mathrm{m}$ spans which are very close to a zero span.

The results of this investigation indicate that short span tensile analysis can be used to assess the quality of pulp fibers. Additional work will be necessary to establish a standard procedure for preparing the handsheets and for conducting the short span tensile test. 


\section{Introduction}

One of the more important fiber properties affecting the mechanical properties of paper is single fiber strength. In order to assess the mean fiber strength of a pulp, it has been necessary to determine the strength of a large number of single pulp fibers. The precise measurement of the strength of single fibers involves a tedious and careful preparation of specimens and specialized equipment for measuring the load-elongation curve for each fiber. The time required to make evaluations for single fiber strengths of pulps is very lengthy and, because of this, single fiber strength evaluations are made only when a critical evaluation of experimental pulps or pulping techniques is necessary.

Recently, single fiber studies have shown that the tensile strength of softwood fibers depends not only on the fibril angle of the $S_{2}$ layer, but also on defects which are distributed randomly along the fibers (1). The probability of a defect occurring within the length of a fiber increases with increasing test length of a fiber test specimen with the result that the mean fiber tensile strength of pulp fibers decreases with increasing test length.

The occurrence of fiber defects depends largely on the chemical and mechanical action process of pulp and paper manufacturing. When paper is recycled, the fibers are subjected to chemical and mechanical action processes a second time, increasing the probability of finding defects in the fibers. Since single fiber strength has a great influence on the strength properties of paper it is desirable to have an estimate of the fiber quality of recycled pulps. Much energy and capital would be wasted if the paper made from a recycled pulp resulted in a paper not being able to meet specific strength specifications. Certainly, the usual single fiber techniques cannot be used for the assessment of fiber quality of recycled pulps. What is needed is a test method which is rapid and simple, yet reliable and reasonably accurate.

As the probability of a defect appearing in a fiber is proportional to the fiber length, it appeared that short span tensile analys is might be a useful technique for assessing pulp fiber quality. In short span tensile testing of paper, the load at failure decreases with increasing span (2). The reason for the decline in load at failure is the decreasing number of fibers traversing the span as the span increases. The rate at which the strength decreases is also believed to be dependent on the average fiber length (expressed as a length weighted average). A pulp having a low weighted mean fiber length would be expected to exhibit a faster rate of decline in load at failure than a pulp with a high weighted mean fiber length. For a given length distribution the load at failure will not decrease as rapidly when the fibers are bonded because bonded fibers will continue to be load bearing when they no longer traverse the span between the clamps.

Consider, then, two pulps having similar fiber length distributions, but one pulp has nearly perfect fibers while the second pulp contains fibers with many defects. The rate of decline of the load at failure in a short span tensile test would be much greater for the pulp containing fiber defects. As a consequence, the slope of the failure load-span length plot would be more negative for the pulp containing fibers with defects than for the pulp with nearly perfect fibers. The object of this investigation was to determine whether short span analys is could be used to assess the quality of pulp fibers. 


\section{Experimental}

A bleached kraft and a sulfite pulp from a common wood source were used in this investigation. Sulfite pulp fibers generally contain more defects than do kraft pulp fibers. The probability of having a similar fiber length distribution for the two pulps was good because they originated from the same wood source. The fiber length distribution was determined for each pulp with the aid of image analysis (3) and the histograms for the pulps are given in Fig. 1.

Handsheets having a weight per unit area of either 2.5 or $5.0 \mathrm{~g} / \mathrm{m}^{2}$ were prepared according to the procedure described in an earlier report (4) except that Whatman filter paper no. 541 was substituted for the cotton linters pulp sheet previously used as the forming medium. Pressing was carried out at $350 \mathrm{kPa}$ (51 $1 \mathrm{~b} / \mathrm{in}^{2}$ ) for 5 minutes. Specimens were $15 \mathrm{~mm}$ wide and approximately $4 \mathrm{~cm}$ long. The specimen was placed in the jaws of the instrument so that one end was centered between the jaws. After the specimen was strained to tensile failure, the jaws were opened and the specimen was moved approximately $1 \mathrm{~cm}$ from the previous test area, reclamped and strained to tensile failure once again. In this manner, it was possible to obtain five to six test results from one test strip.

The instrument used for making the short span tensile tests was specially designed for the purpose. The instrument was designed to provide a nominally constant rate of jaw separation. Transducers for the simultaneous measurement of load and jaw separation were suitably located on the instrument and the signals were recorded on an X-Y recorder. The instrument was previously calibrated for load measurement with dead weights while the linear transducer was calibrated with feeler gauges. The clamping pressure was 70 psi and was determined by observing the zero span load as a function of clamping pressure. At pressures below 70 psi slippage occurred and the zero span load value was low. At pressures substantially above 70 psi, considerable fiber damage occurred and, again, the zero span load value was low. The pressure chosen was at a point where the zero span load value was at a maximum.

The rate of jaw separation was adjusted for each span length so that the rate of elongation was $3 \%$ per second. This was the lowest strain rate possible which would allow for an identical strain rate for all of the span lengths investigated. Load elongation curves were obtained for span lengths of 25, 50, $75,100,200,300,400$, and $500 \mu \mathrm{m}$. A11 tests were conducted in a room having a controlled atmosphere of $23^{\circ} \mathrm{C} \pm 1{ }^{\circ} \mathrm{C}$ and $50 \% \mathrm{RH} \pm 2 \% \mathrm{RH}$. The results of this investigation are given in Tables $1-4$. 
4. Results and Discussion

There are four factors which affect the failure load in short span tensile testing of paper, fiber strength, fiber length distribution, interfiber bond strength.and fiber orientation. It has been speculated that these four factors could be assessed by means of short-span tensile testing (5). During the course of this discussion, an attempt will be made to demonstrate that the assessment of these four factors by short-span tensile testing may be deceptive.

Most paper consists of multiple layers of fibers. As the thickness of the paper increases it is quite possible that a significant number of fibers, at or near the center of the paper, are not clamped sufficiently resulting in fiber pul1-out. Fibers which are pulled out instead of broken in tensile failure contribute little to the breaking load and as a consequence, the test results will be lower than expected. The obvious procedure for avoiding fiber pull-out is to increase the clamping pressure, however, high clamping pressures result in fiber damage which, in turn, culminates in low tensile failure loads. An apparent alternative is to use very low density paper, consisting of very few layers of fibers, thus avoiding poorly clamped fibers. Such paper is commonly referred to as a 2-D sheet. In this study, handsheets having a mass per unit area of $2.5 \mathrm{~g} / \mathrm{m}^{2}$ and $5.0 \mathrm{~g} / \mathrm{m}^{2}$ were used.

A second important variable in preparing paper for short-span tensile testing is interfiber bonding. As bonding increases, more and more fibers become load-bearing resulting in higher loads at the break, especially at the longer spans. This means that the slope of the breaking load-span length plot would increase (become less negative) as the amount and strength of interfiber bonding increased. Since the object of this investigation was to determine whether the fiber quality of a pulp could be assessed by the magnitude of the slope of the breaking load-span length plot it is essential that the interfiber bonding of the test sheets be at an equivalent level for all test sheets.

Interfiber bonding may affect the slope of the breaking load-span length plot in yet another way. All things being equal, the slope of the breaking load-span length plot should decrease with increasing number of defects in the fibers. In instances where defects are located within the bond area, it is very likely that the response of the defects to tensile stresses will be appreciably different than when located outside the bond area. In fact, in certain instances, a defect might be essentially "repaired" or "healed" when located within the confines of an interfiber bond.

The wet plasticity of pulp fibers, at the time of sheet preparation, should be equivalent for all pulps to be tested. If the wet plasticity for two or more pulps is significantly different, then the bonded area will be greatest for the pulps having the highest wet plasticity as the ability of one fiber to conform with another fiber increases with wet plasticity. For pulps having an equivalent number of defects, the probability of finding a defect in an unbonded area is greatest for the pulp having the lowest wet plasticity since less fiber area is involved in bonding. Unless the relative bonded area is at an equivalent level for all pulps, assessment of fiber quality by short span analys is could be illusory. 
The results of failure load for the various span lengths are plotted in Figs. 2 and 3 for 2.5 and $5.0 \mathrm{~g} / \mathrm{m}^{2}$ sheets respectively. The failure load declines as the span increases from 100 to $500 \mu \mathrm{m}$, however, the failure load at 50 and $75 \mu \mathrm{m}$ was usually lower than at the $100 \mu \mathrm{m}$ span length. This behavior between 50 and $100 \mu \mathrm{m}$ was not as apparent with the $5 \mathrm{~g} / \mathrm{m}^{2}$ sheets. The reason for this behavior is not known at this time. There is a possibility that the tensile response to straining may change appreciably as the span length approaches the width dimensions of the fibers. The results from this investigation suggest that span lengths less than $100 \mu \mathrm{m}$ should not be used in short-span tensile analysis.

When the results were plotted on a semi-log scale, good linear plots were obtained (Figs. 4 and 5 ). Presumably, extrapolation of the plot to zero span approximates the true zero span strength of the sheets. The coefficient of correlation, slopes and y intercepts for all of the plots are given in Table 5. The $y$ intercepts for the $5.0 \mathrm{~g} / \mathrm{m}^{2}$ sheets are approximately twice that for the $2.5 \mathrm{~g} / \mathrm{m}^{2}$ sheets which indicates that no fiber slippage occurred during the straining of the sheets.

The slopes for the failure load-span length plots for the unbeaten pulps were essentially the same regardless of the mass per unit area of the sheets or the type of pulp. This would indicate that the fiber quality of both pulps was the same. However, since sulfite pulp fibers are weaker than kraft pulp fibers, some factor previously unaccounted for must have had an effect on the test results.

Unbeaten sulfite pulps swell more readily in water than do kraft pulps (6). As a result, the sulfite pulp fibers have a greater wet plasticity than the kraft pulp fibers and the sulfite fibers are able to conform to each other better during wet pressing. This results in better bonding between the fibers of unbeaten sulfite than in unbeaten kraft pulp. Therefore, more load bearing fibers are present in unbeaten sulfite sheets at the longer spans than in the kraft sheets and the slope of the log failure load-span length plots for the sulfite sheets should be less negative than the slope for the kraft sheets. The fact that the slopes for both the unbeaten sulfite and kraft sheets are nearly identical may be fortuitous. In light of the large impact interfiber bonding apparently has on short-span testing, it is imperative that all test sheets have an equivalent degree of bonding, otherwise the results could lead to illusory conclusions.

Upon beating both pulps in a laboratory beater in order to have both pulps at more nearly the same wet plasticity, great differences in slopes were observed between the sulfite and kraft pulps. The slope for the kraft pulp increased appreciably after beating while no change in slope occurred for the sulfite pulp. One could argue that beating had no effect on the wet plasticity of the sulfite pulp and no decrease in slope would be expected after beating. However, the breaking strength for $10 \mathrm{~g} / \mathrm{m}^{2}$ sheets of unbeaten sulfite was $58 \mathrm{~g}$ before and $246 \mathrm{~g}$ after beating. Similarly, the unbeaten kraft had a strength of $121 \mathrm{~g}$ before beating and $544 \mathrm{~g}$ after beating. The breaking strengths were determined on a commercial constant rate of elongation tensile tester according to TAPPI T494 0S-70 with the exception $15 \mathrm{~mm}$ and not $25 \mathrm{~mm}$ wide specimens were used. The mean breaking strengths reported above were based on a minimum of eight specimens. 
The data for the 100-500 $\mu \mathrm{m}$ range were reanalyzed since the results indicated that spans less than $100 \mu \mathrm{m}$ ought not be used. The results of that analys is are given in Table 5. In most instances there was an increase in the coefficient of correlation, increases in the slope and appreciable increases in the $y$ intercept. The greatest changes occurred with the $2.5 \mathrm{~g} / \mathrm{m}^{2}$ handsheet results. Although increases in slopes were observed when only the 100-500 $\mu \mathrm{m}$ range was analyzed, the ratio between the sulfite and kraft slopes was essentially unchanged, ind icating the range of span lengths investigated will not affect the assessment of fiber quality providing the span length range is identical for all the pulps. 


\section{Conclusions}

The results indicate that an assessment of fiber quality by short span tensile analys is is feasible providing the wet plasticity of the pulp fibers at the time of handsheet preparation is such as to provide equivalent interfiber bonding for all types of pulps. It also appears that fiber slippage can be virtualiy el iminated by using very low density sheets in the range of $5.0 \mathrm{~g} / \mathrm{m}^{2}$. It appears that span lengths less than a certain minimum value should not be used as fiber dimensions become a factor in the test results. In this investigation, the minimum span length appeared to be $100 \mu \mathrm{m}$. Since the assessment of fiber quality by short span tensile analys is is approximately identical for both 2.5 and $5.0 \mathrm{~g} / \mathrm{m}^{2}$ sheets, the easier to prepare $5.0 \mathrm{~g} / \mathrm{m}^{2}$ would be preferred. 


\section{Bibliography}

1) Page, D. H. and El-Hosseiny, F., Svensk Papperstidning No. 14, 471 (1976).

2) Cowan, W. F. and Cowdry, E. J. K., TAPPI 57, No. 2 90-93 (1974).

3) Graminski, E. L. and Kirsch, R. A., Image Analys is in Paper Manufacturing, Proceeds of IEEE Computer Society Conference on Pattern Recognition and Image Processing, p. 137-143, June 6-8, 1977.

4) Smith, J. C. and Graminski, E. L., Characterizing the Interfiber Bond Strengths of Paper Pulps in Terms of a Breaking Energy. NBSIR 76-1148, Oct. 15, 1978.

5) Cowan, W. F., Short Span Tensile Analysis, Pulmac Instruments Ltd., Montreal, Canada, 1975.

6) Scallan, A. M., In "Fiber-Water Interactions in Paper-Making", Trans. of the Symposium held at Oxford: September, 1977. Edited by the Fundamental Research Committee, Technical Division, The British Paper and Board Industry, Federation London, pp. 9-27, 1978. 



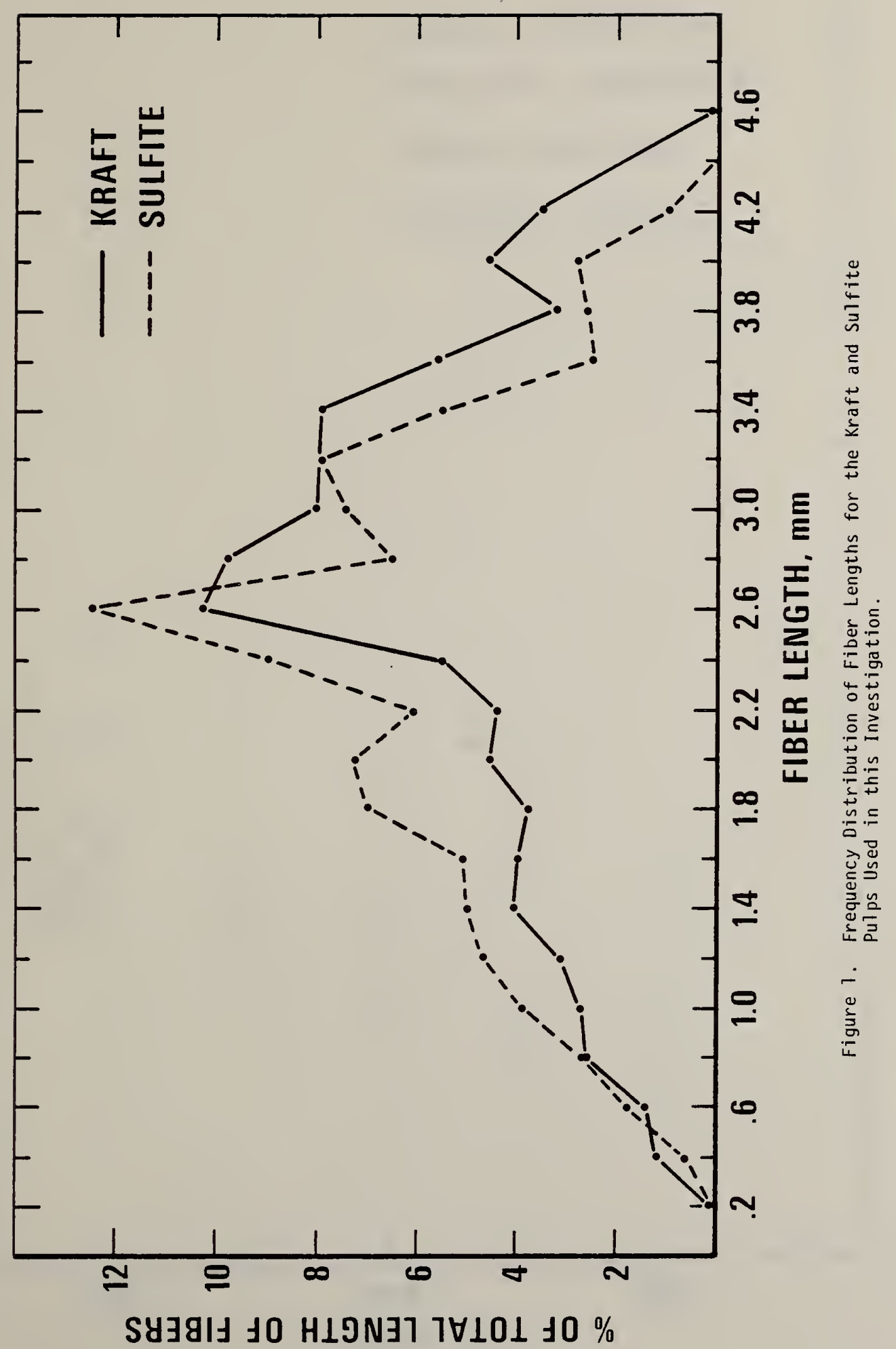





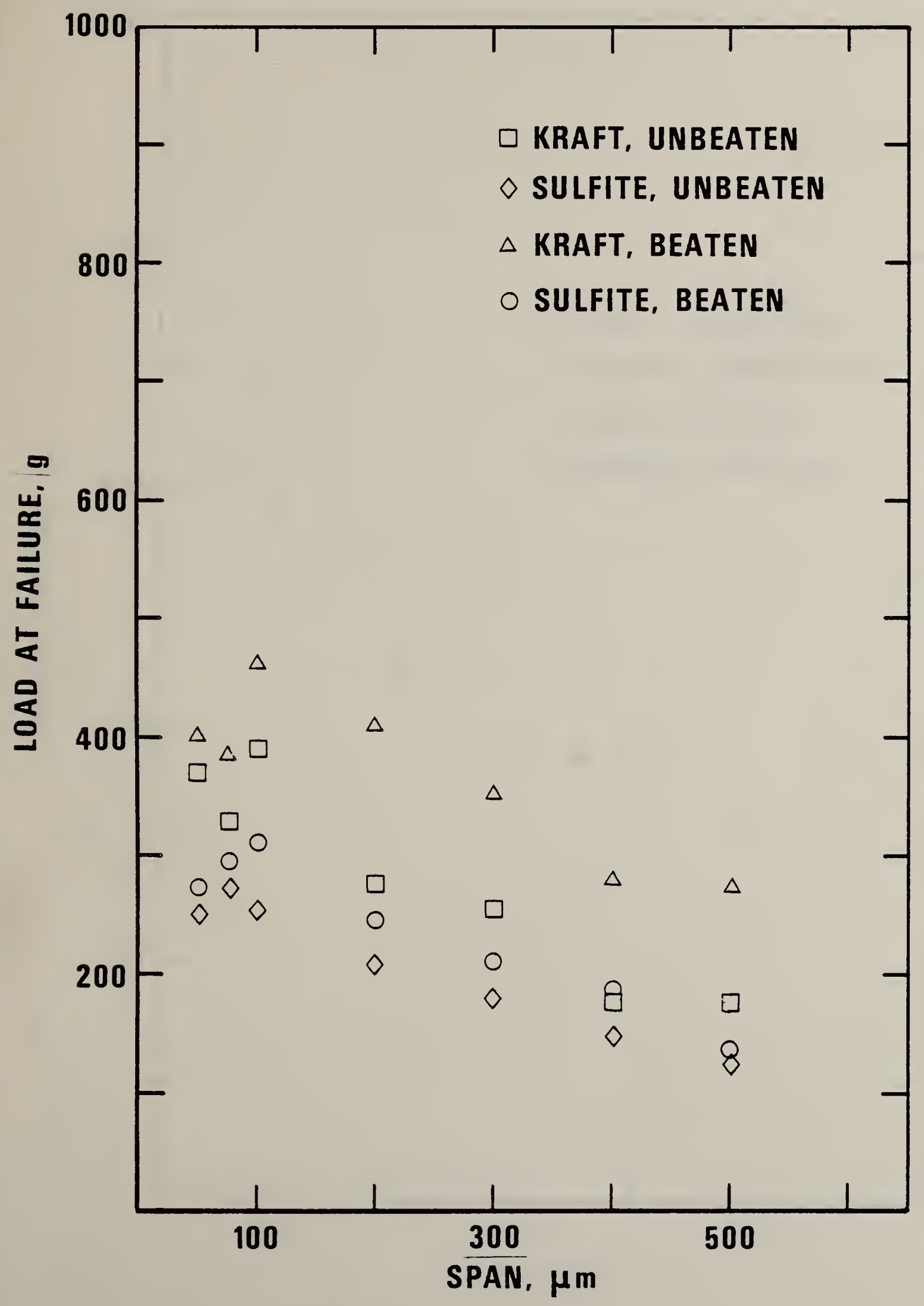

Figure 2. Change in failure load with increasing specimen length for $2.5 \mathrm{~g} / \mathrm{m}^{2}$ handsheets made from unbeaten and beaten pulps 



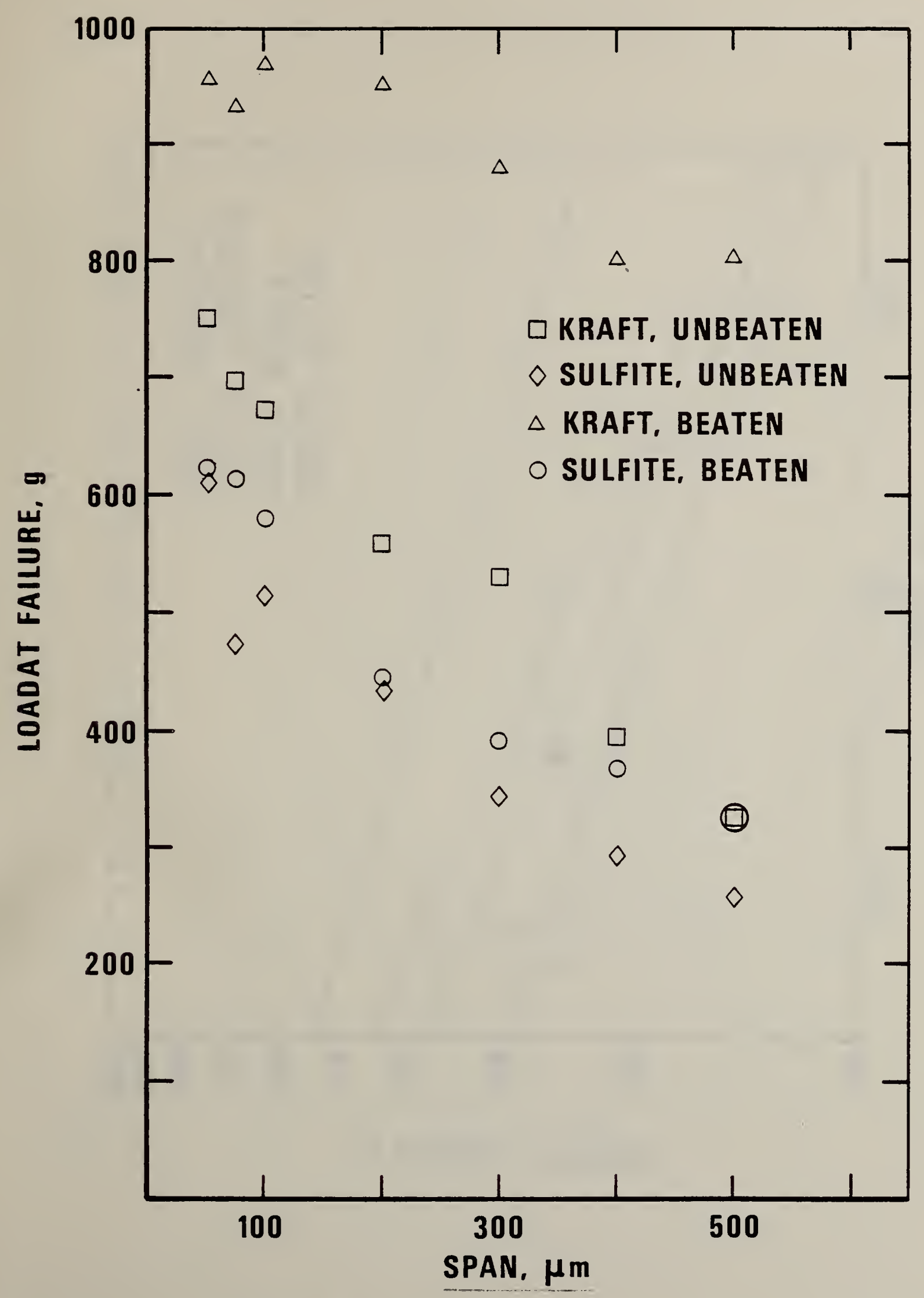

Figure 3 Change in failure load with increasing specimen length for $5.0 \mathrm{~g} / \mathrm{m}^{2}$ handsheets made from unbeaten and beaten pulps 



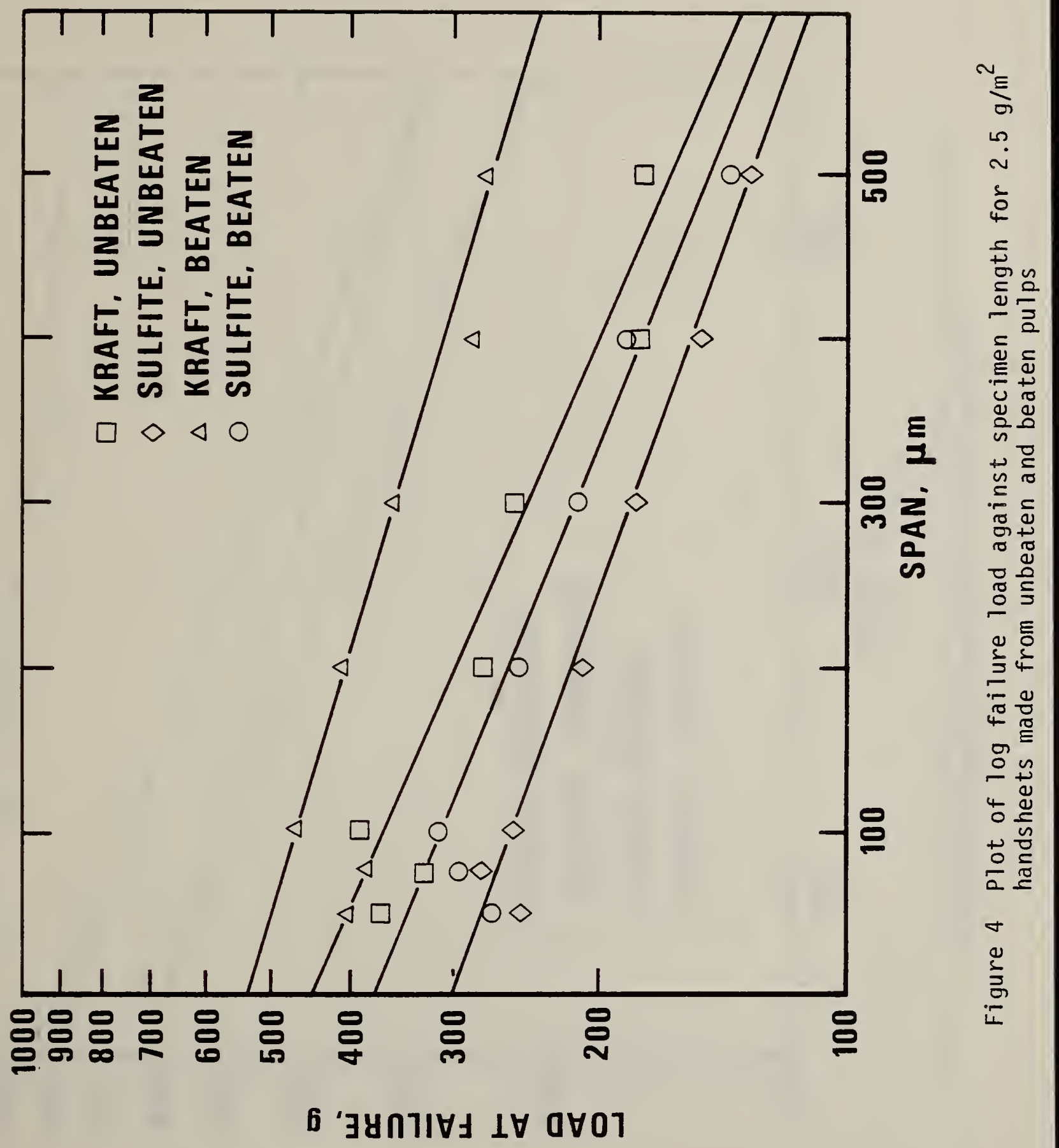





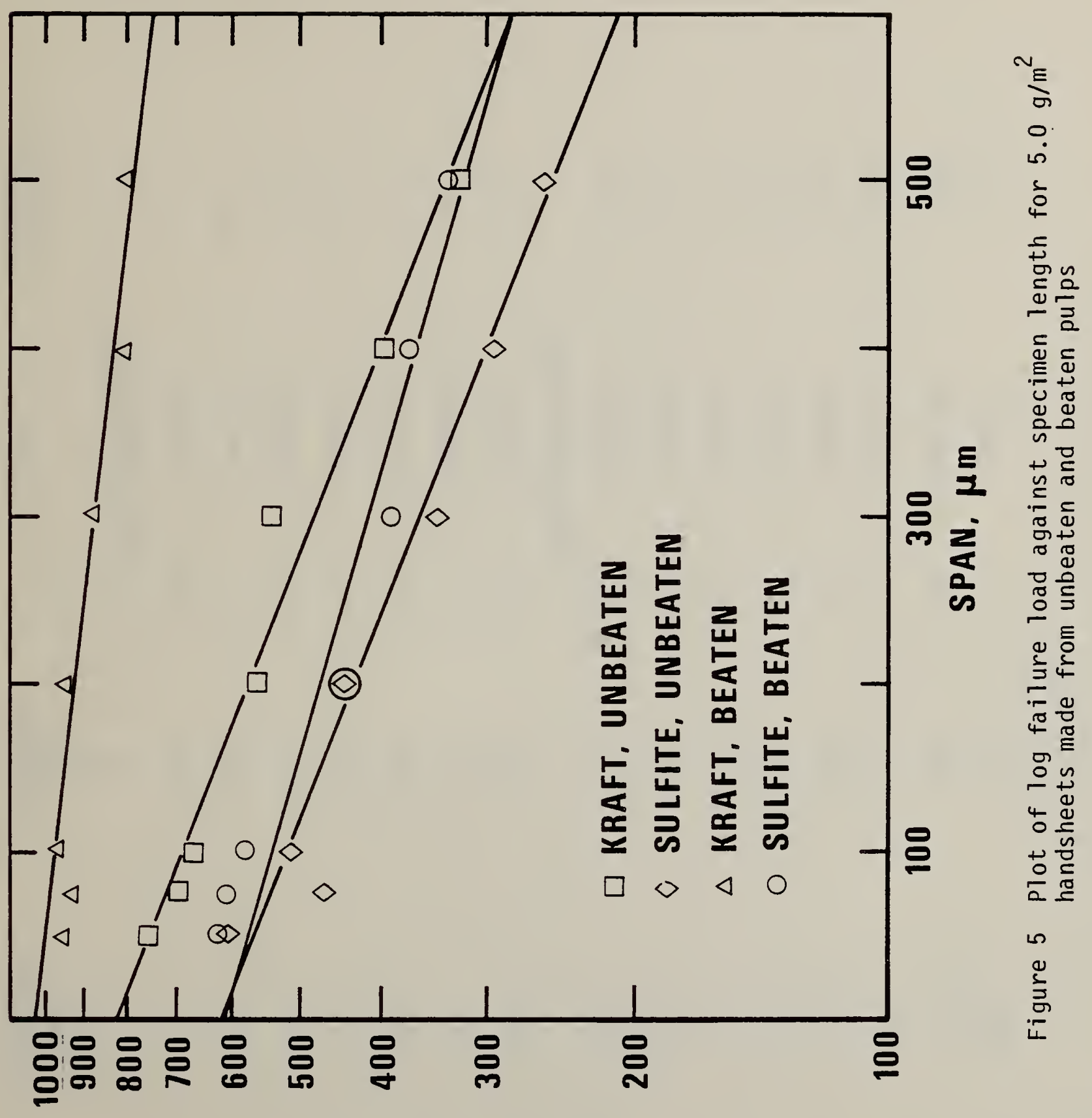

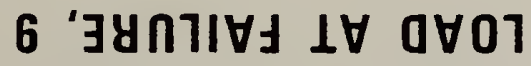





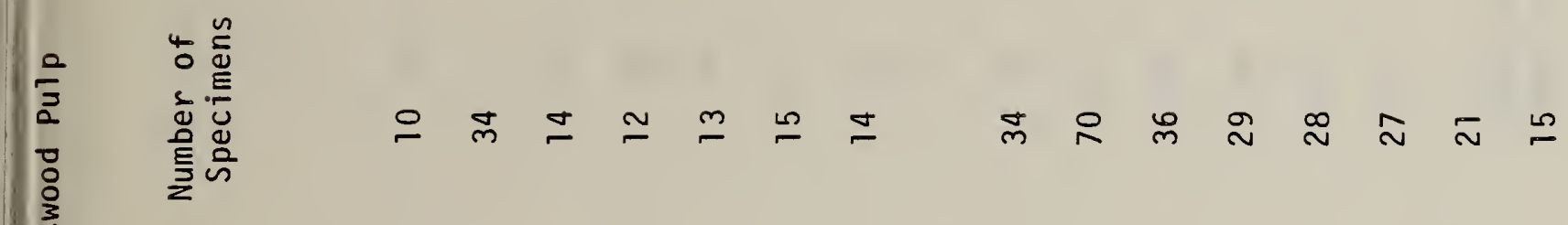

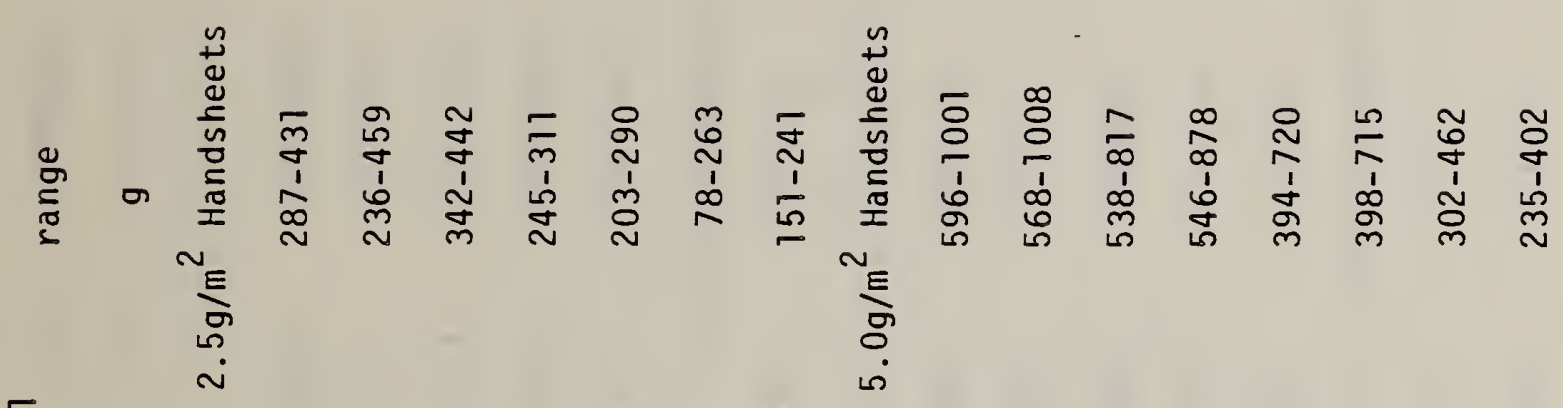

유 ๘

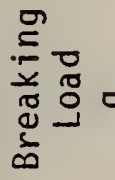

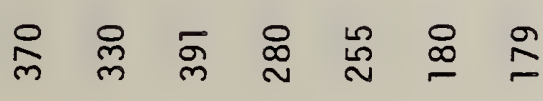

م

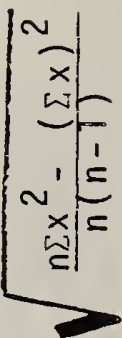

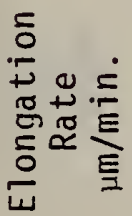

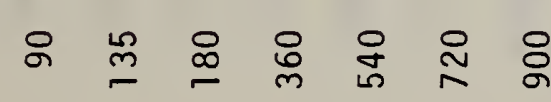

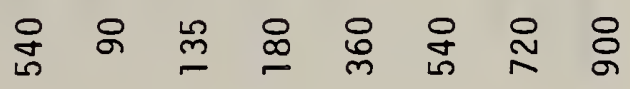

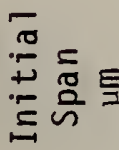

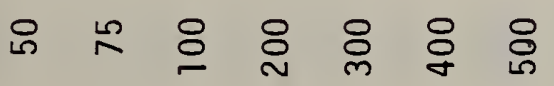

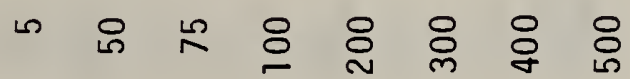


$4 \stackrel{n}{E}$

造

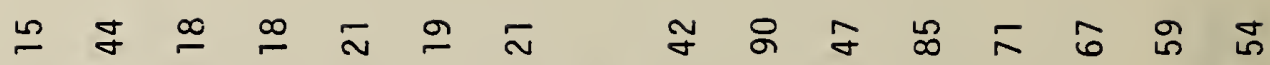

$\frac{2}{3}$

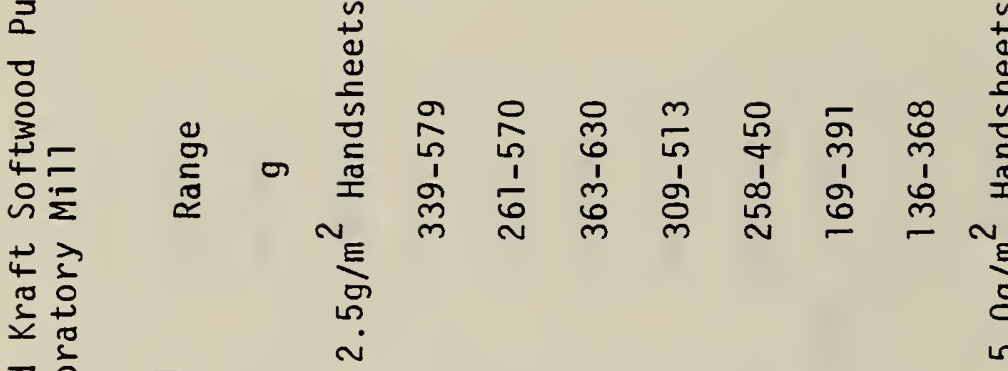

욜

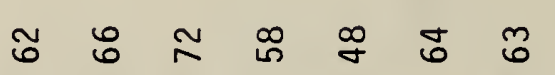

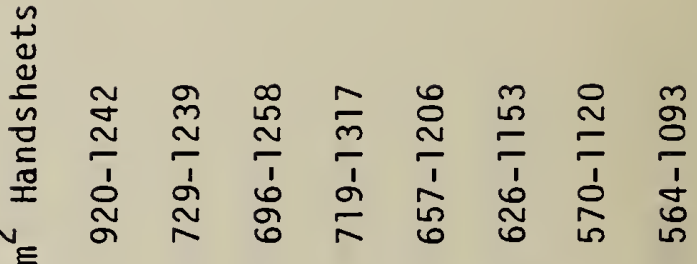

\&

$\bar{\infty} . \approx$

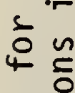

욜

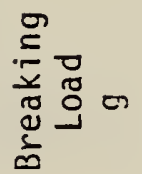

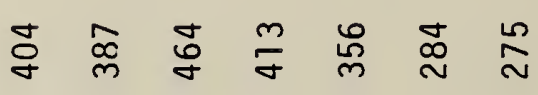

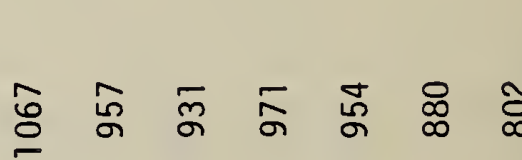

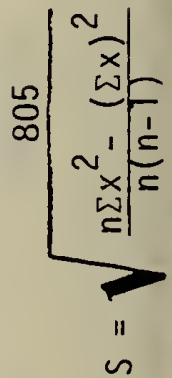

ㅎํㄴ

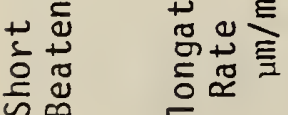

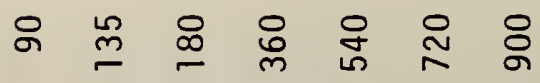

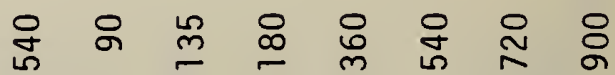

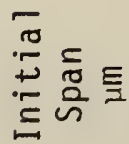

요요요요요용

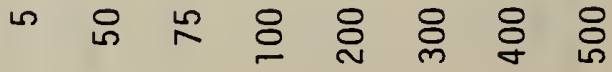




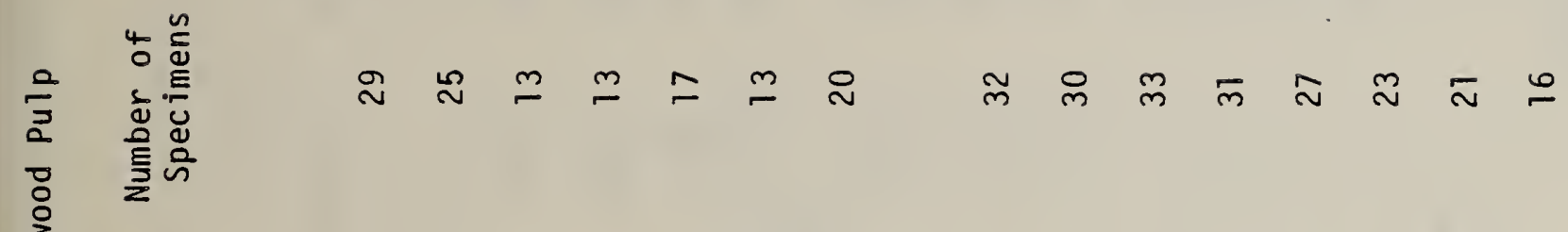

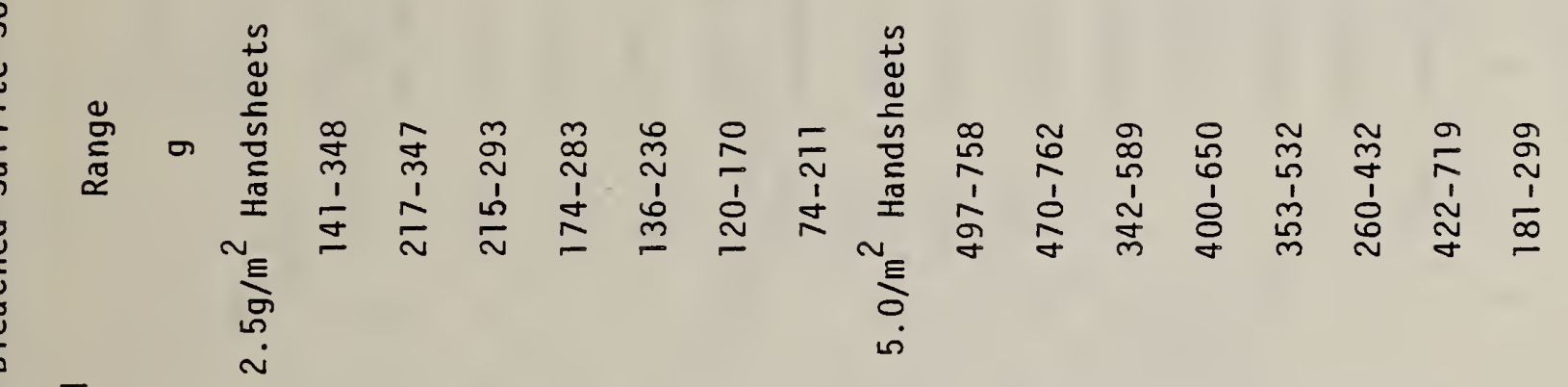

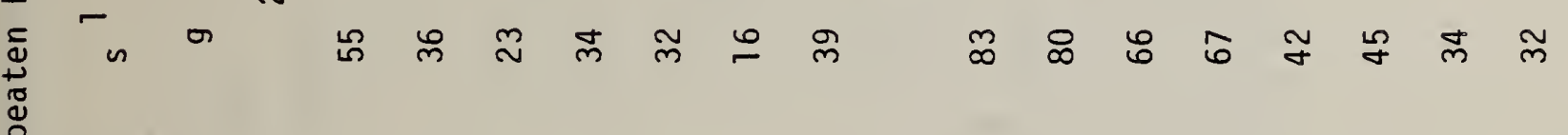

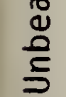

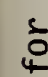

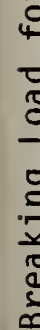

믿

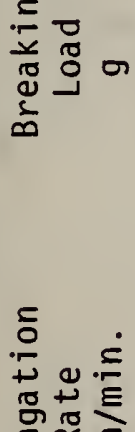

范哭主

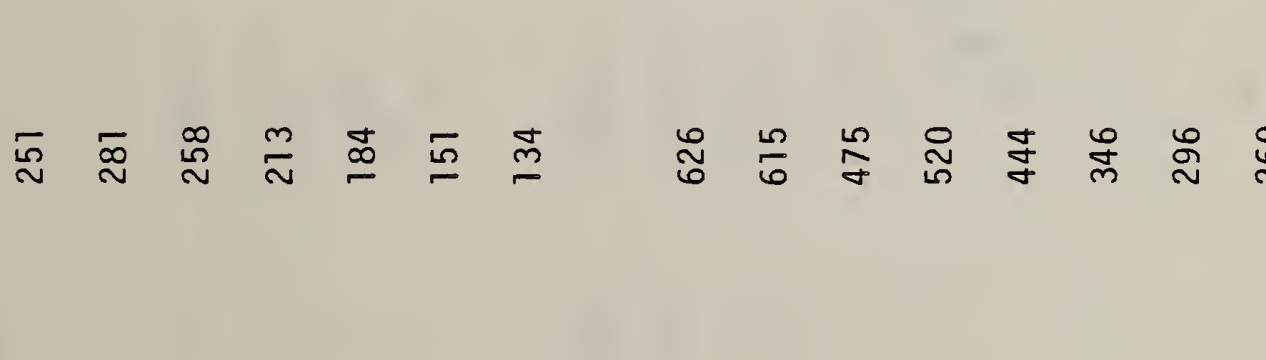

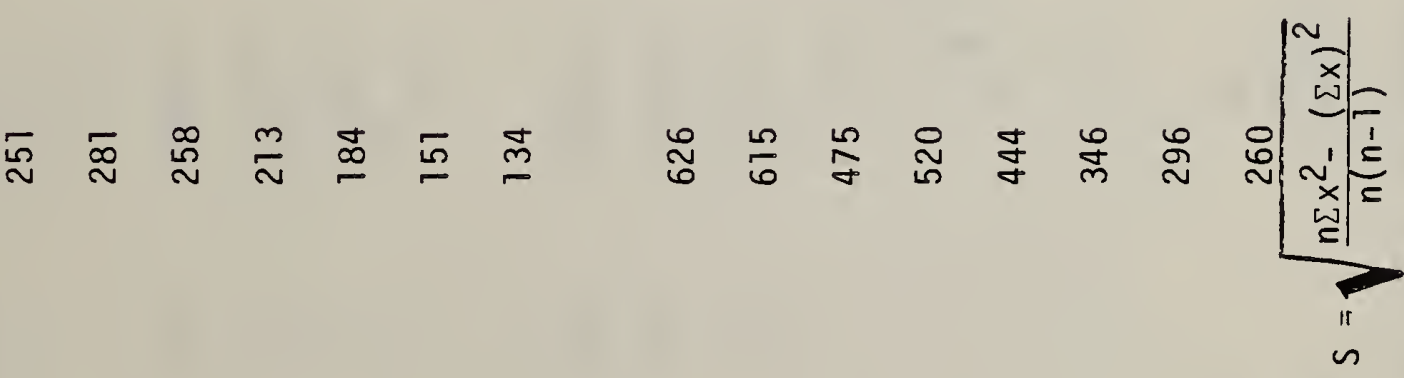

๘

$\frac{\pi}{5}$

$\sqrt[\pi]{\square}$

5
$\frac{1}{2}$

\& $\stackrel{\infty}{=}$

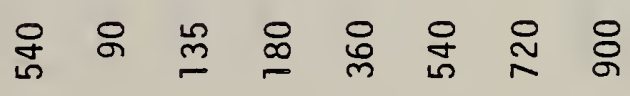


$\leftarrow \stackrel{\sim}{\frac{0}{E}}$

工.

के

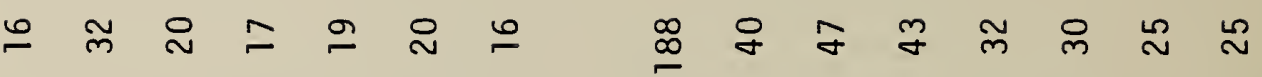

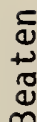

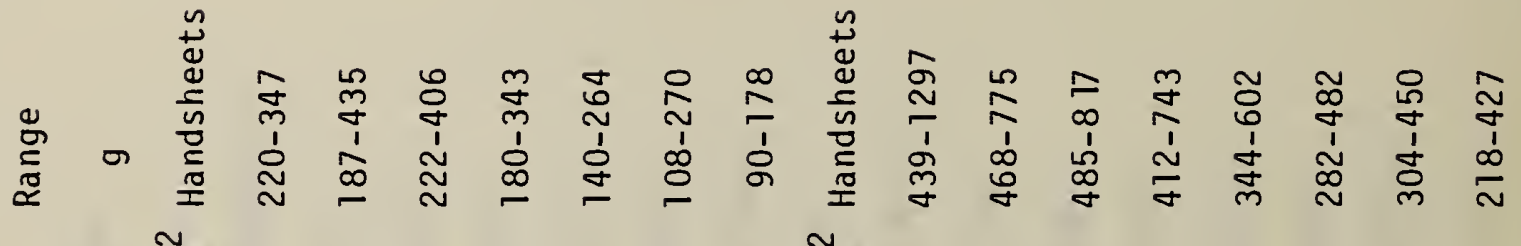

$\frac{2}{2}$

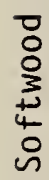

啇

in o

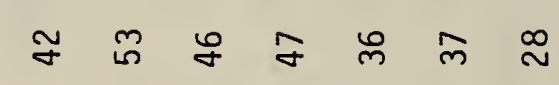

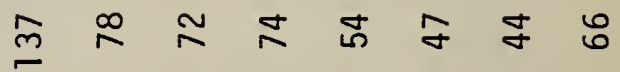

$\stackrel{\oplus}{\stackrel{5}{5}}$

要

过

号

궁

$\infty$

\&

ミ

in

ㄴำ

రृ

on

돌

这

ᄃิ

के

ह वे

苋里

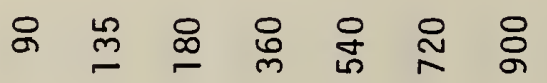

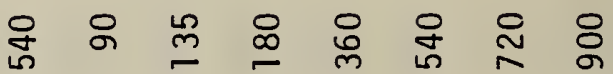

जे०

䓂高

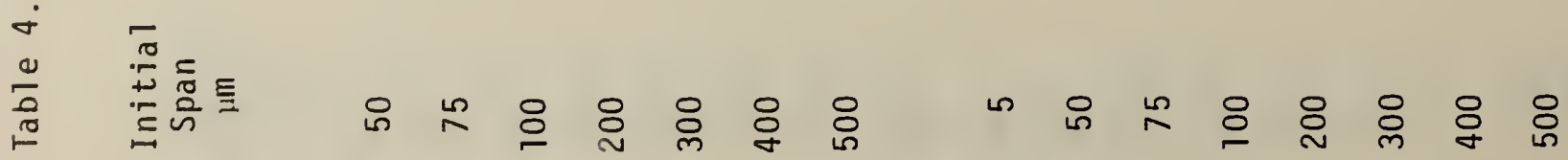



NBS-IILA (REV. 9-70)

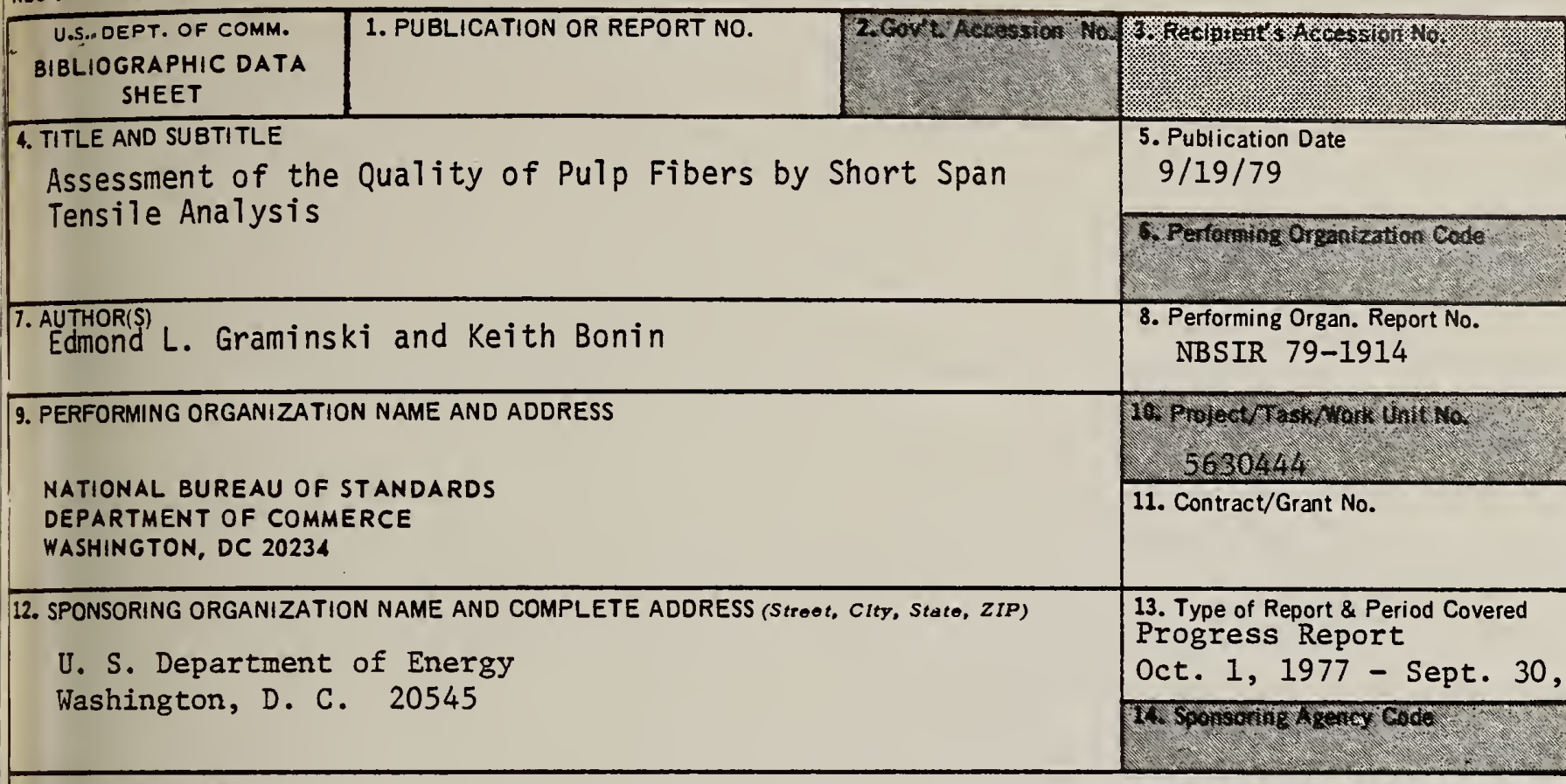

Document describes a computer program; SF-185, FIPS Software Summary, is attached.

16. ABSTRACT (A 200-word or lese factual summary of most sigrificant information. If document includes a significant bibliography or literaturo survey, mention it horo.J

Fiber stirength is an important iactor in paper strength, but despite its importance ffber strength is rarely assessed as it invoives the tedious and time consuming testing of singie ffuers. In the recycling of paper. espectally of the abundant law grades af wasts paper, the question of ffber qual ity ziways arfses. The inabitity: to monitor fiber quality of recyel ed pulp, especiall y from. Tow grade waste paper has led to the practice of utilizing this pulp only for low grade papers regardless of the actual quality of the pulp fibers. Unfortunateiy. toere is a limited denand for Tou grade papers. Increased utfitzatfon of low grade waste paper could be enhanced if the ffiber quality af the resjeled pulps could be moattored routtieiy. As the strength of ffbers is affected by defeess that are randomly distributed among: and within ffbers tt appeared short span tensile test might orovide means for assessing fiber quality. In short spar tensite testing of fibrous weos the load at the break declines as the spar increases. The rate or dectine is partly controlled by the flber Tengeh distribution. Since the probabitity of locating derects in fibers increases with increasing span Tengths the rate of decline in web strength with increasing span lengths should be a function of ifber quality for a specific ffber Tength dfstributton;, alt things being equat. The results of this investigatton indicate that the rate of decline in web strength with incressing span length is indest a function of ffber quality. It appears that the best method could be used to monitor fiber quality routineily.

17. KEY WORDS (six to twelve ontriee; alphabetical order; capitalize only the first lettor of the first key word unlese a proper name; sopereted by semicolons)

Fiber length distribution; fiber strength; interfiber bonding; recycled pulps; short span tensile analysis; zero span tensile.

18. AVAILABILITY

For Official Distribution. Do Not Release to NTIS

Order From Sup. of Doc., U.S. Government Printing Office, Washington, DC 20402, SD Stock No. SNOO3-003-

Order From National Technical Information Service (NTIS), Springfield, VA. 22161

\begin{tabular}{|l|c|}
\hline $\begin{array}{l}\text { 19. SECURITY CLASS } \\
\text { (THIS REPORT) } \\
\text { UNCLASSIFIED }\end{array}$ & $\begin{array}{c}\text { 21. NO. OF } \\
\text { PRINTED PAGES } \\
19\end{array}$ \\
\hline $\begin{array}{l}\text { 20. SECURITY CLASS } \\
\text { (THIS PAGE) } \\
\text { UNCLASSIFIED }\end{array}$ & $\begin{array}{l}\text { 22. Price } \\
\$ 3.00\end{array}$ \\
\hline
\end{tabular}




